\title{
3D character of backward erosion piping
}

\section{Géotechnique}

\author{
Vandenboer, K., van Beek, V.M., Bezuijen, A. \\ doi: 10.680/jgeot.16.P.091
}

\section{Introduction}

Backward erosion piping is an important failure mechanism for cohesive water-retaining structures founded on a sandy aquifer. A local disruption of the downstream top layer leads to concentrated seepage flow, which may result in the onset of erosion at that location. The erosion process continues in the upstream direction, resulting in the formation of shallow pipes in the sand layer. Eventually, the pipe forms a direct connection between upstream and downstream, which may result in a (partial) collapse of the water-retaining structure (fig. 1).

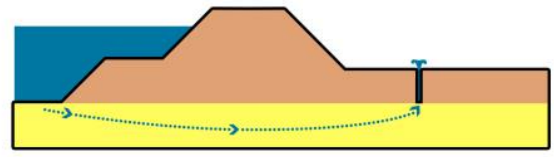

Phase 1: Seepage

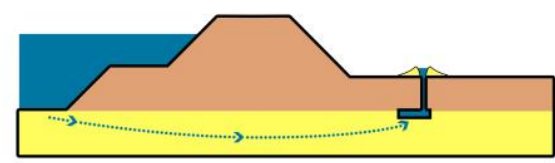

Phase 2: Backward erosion

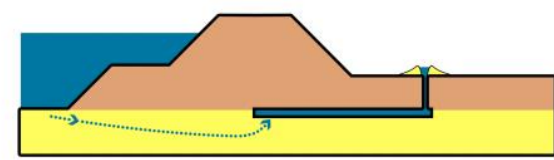

Phase 2: Backward erosion

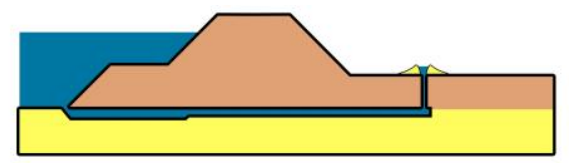

Phase 3: Widening of the pipe

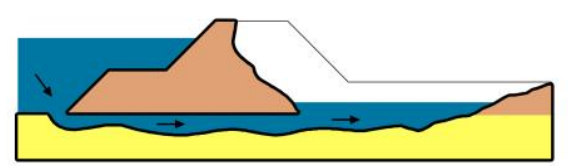

Phase 4: Dike failure

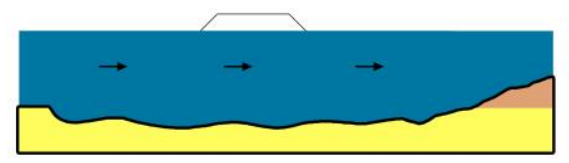

Phase 5: Dike breach

Fig. 1 Schematic drawing backward erosion piping

Current research with the aim to understand the erosion mechanisms during piping and to improve the existing formulae for piping prediction is often based on experimental or numerical studies with an arbitrarily chosen limited model width (Miesel 1978; De Wit, Sellmeijer et al. 1981; Sellmeijer 1981; Hanses, Müller-Kirchenbauer et al. 1985; Townsend, Bloomquist et al. 1988; van Beek, Knoeff et al. 2011; Allan, Peirson et al. 2015; Koito, Horikoshi et al. 2016; Bersan, Koelewijn et al. 2017), without knowing the influence of this limitation. This technical note presents a series of small-scale experiments to address and quantitatively evaluate the implications of modelling the 3D piping process with a limited model width.

\section{Materials \& method}

In laboratory conditions, the sandy aquifer is built in a pvc box, the cohesive water-retaining structure is replaced by an acrylate plate (see fig. 2 a-d) with a fixed circular opening 
representing the locally punctured top layer and the hydraulic gradient is applied by means of an upstream and downstream reservoir with adjustable water levels.

The sand layer has a length $L_{\text {tot }}$ of $0.4 \mathrm{~m}$, a height $H$ of $0.1 \mathrm{~m}$ and a seepage length $L$ of $0.3 \mathrm{~m}$. In order to study the importance of 3D modelling and the influence of simplification to a 2D model in backward erosion piping, a comparison between $2 \mathrm{D}$ and $3 \mathrm{D}$ models is essential.
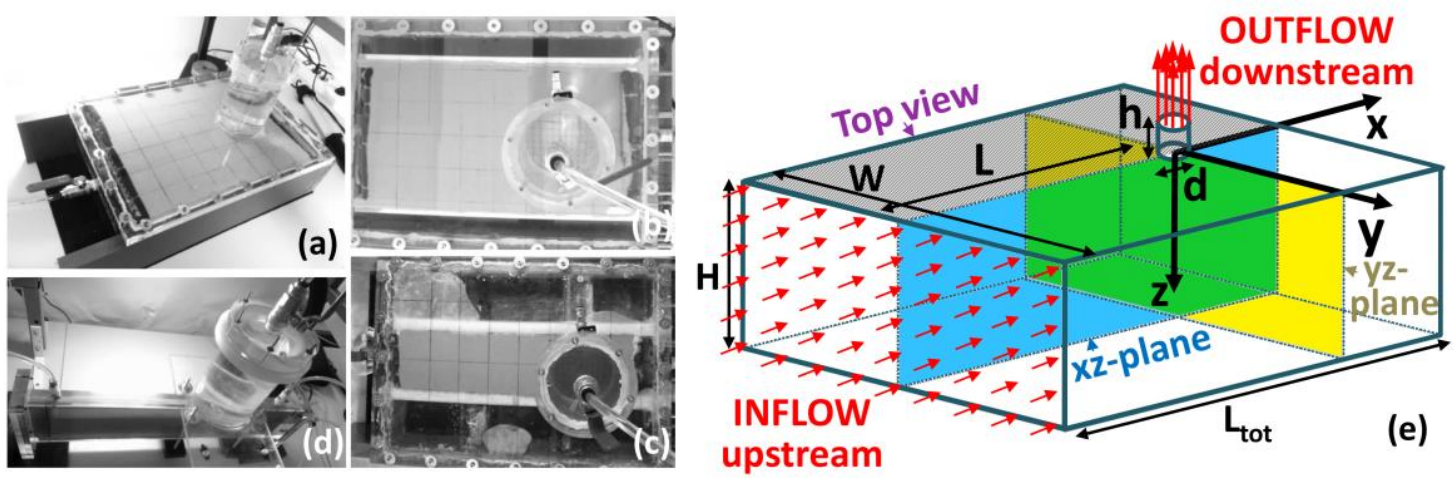

Fig. 2 Experimental setup: $W=0.3 \mathrm{~m}(\mathrm{a}), \mathrm{W}=0.2 \mathrm{~m}(\mathrm{~b}), W=0.1 \mathrm{~m}(\mathrm{c}), W=0.01 \mathrm{~m}(\mathrm{~d})$ and model geometry (e)

Theoretically, an infinitesimal model width must be chosen in order to perform a 2D experiment and an infinite width would be required for a 3D experiment, while in practice a finite width is used. This technical note investigates the influence of the model width, which is a measure for the presence of the third dimension, by performing a series of experiments with varying model widths: $0.3 \mathrm{~m}, 0.2 \mathrm{~m}, 0.1 \mathrm{~m}$ and $0.01 \mathrm{~m}$ (7, 2, 3 and 3 experiments respectively) (fig. 2 a-d).

The circular exit represents a local crack in the cohesive protective layer making the system prone to erosion. It has a height $\mathrm{h}$ of $10 \mathrm{~mm}$ (thickness of the acrylate plate near the exit) and a diameter d of $5 \mathrm{~mm}$, which is 20 times the mean grain size of the sand, sufficient to prevent blocking of the hole (Miesel 1978; Müller-Kirchenbauer 1978; van Beek, Bezuijen et al. 2014). Furthermore, a circular exit enables reproducible pipe formation unlike a plane or ditch type exit where neither the origin location, nor the number of pipes is controllable (van Beek, Bezuijen et al. 2013).

The sand sample consists of a uniform, poorly-graded silica sand, Mol M32, with a mean grain size diameter of $250 \mu \mathrm{m}$, which is prepared homogeneously at a relative density of more or less $80 \%$ (with a minimum and maximum porosity of 0.3474 and 0.4465 respectively) resulting in an average hydraulic conductivity of $\mathrm{k}=3.210^{-4} \mathrm{~m} / \mathrm{s}$.

Initially the hydraulic head difference $\Delta \mathrm{H}$ is null and it is increased in steps of $5 \mathrm{~mm}$ or $10 \mathrm{~mm}$ every 5 minutes, as long as no erosion is noticed. When sand grains start to move, the hydraulic head is kept constant; if no erosion is observed for at least 5 minutes (equilibrium), the hydraulic head is further increased. The critical hydraulic head for initiation of erosion $\Delta H_{\text {init }}$ is defined as the moment at which the exit hole is filled and sand grains start being ejected and form a submerged crater around the exit hole. 
The hydraulic head is further increased until the critical hydraulic head for progression $\Delta H_{\text {prog }}$ is exceeded, i.e. no equilibrium state is achieved anymore and the pipe grows until it reaches the upstream filter, after which the test is stopped.

The flow rate is continuously measured by collecting and measuring the amount of water mass seeping out from the exit hole.

\section{Results \& discussion}

Fig. 3 a-d show some development stages for the examined model widths. It can be seen that the meandering character of the pipe increases with the model width. For larger widths, water supply towards the pipe originates from a wide area upstream and flow lines are bended towards the pipe. Therefore, the path with least resistance can be followed leading to meandering (Townsend, Bloomquist et al. 1988; Weijers and Sellmeijer 1993). For small model widths on the other hand, water flows in a rather straight line so meandering decreases. In case of a width of $0.01 \mathrm{~m}$, meandering is simply not possible.

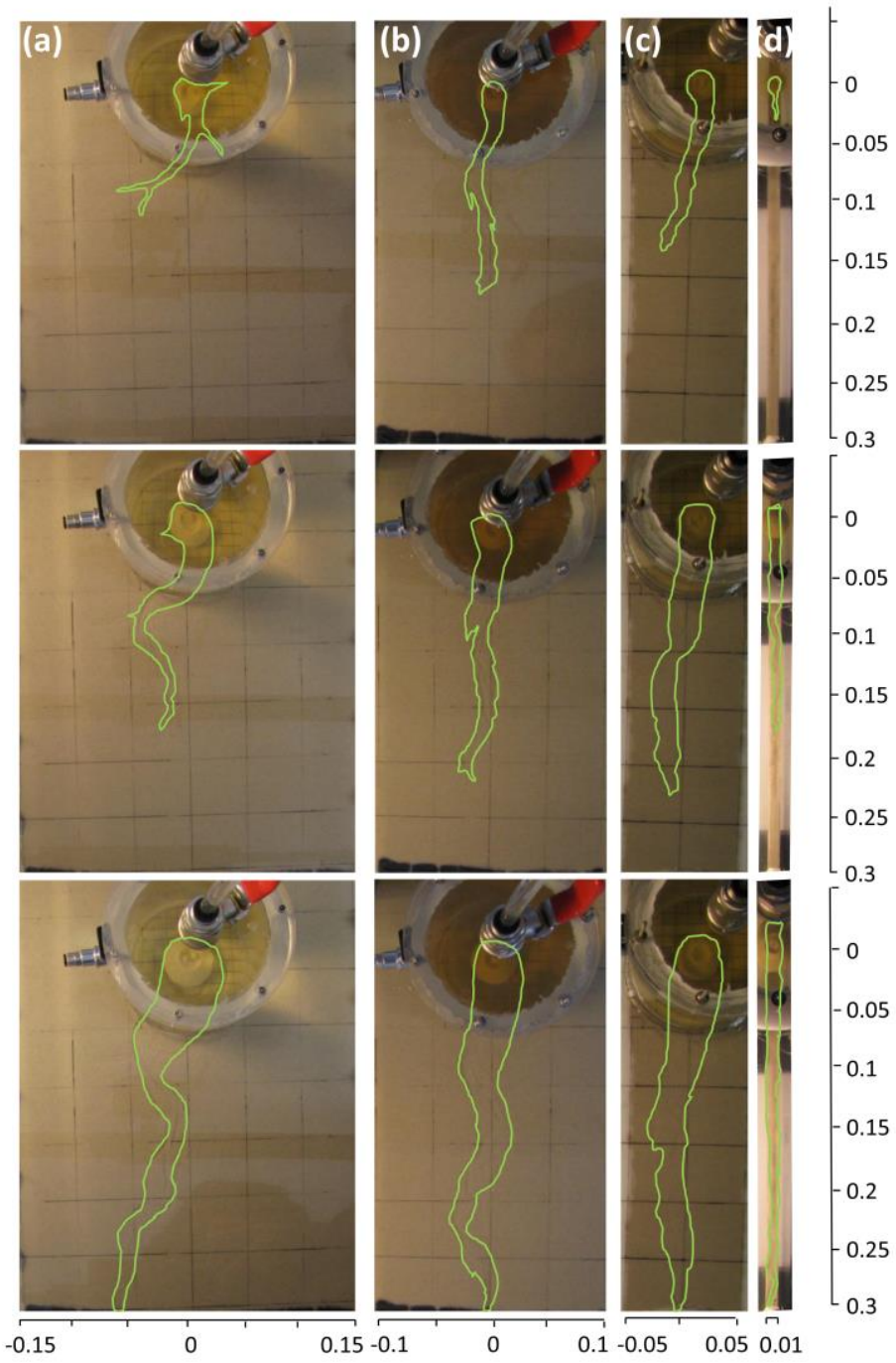

Fig. 3 Different stages of pipe development for a model width $W=0.3 \mathrm{~m}(\mathrm{a}), \mathrm{W}=0.2 \mathrm{~m}(\mathrm{~b})$, $\mathrm{W}=0.1 \mathrm{~m}(\mathrm{c})$ and $\mathrm{W}=0.01 \mathrm{~m}(\mathrm{~d})$ 
The pipe width seems to be independent of the model width, unless it is physically restricted such as in the experiment with $W=0.01 \mathrm{~m}$. For larger model widths, the pipe width is not constant along its length and the maximum width is substantially larger than the diameter of the exit hole, resulting from radial flow towards the pipe.

In the field, the defect is located in a cohesive soil instead of acrylate and may erode simultaneously with the piping process (Marot, Regazzoni et al. 2011); however the influence of such an extendible exit on the piping development is outside the scope of this study.

Fig. 4 shows that the critical hydraulic head $\Delta H_{c r}$ and average gradient $i_{\text {avg,cr }}=\Delta H_{c r} / L$ for piping initiation and piping progression both decrease with increasing model width. This proves that the horizontal water flow parallel to the water-retaining structure is an important driving force for erosion: a larger experimental width involves a higher flow towards the pipe, which yields high local gradients both at the pipe tip and in the pipe and thus provokes further erosion of sand grains.

The observed trend of critical head and model width is not linear and seems to stagnate for an increasing model width. The bended flow paths originating far from the exit hole become too long so their contribution to the amount of flow becomes negligible. To determine the minimum model width to properly reproduce a $3 \mathrm{D}$ configuration without boundary effects, the analysis needs to be extended for larger model widths which was practically impossible in the current study. A numerical study considering similar dimensions and materials did identify this minimum model width (Vandenboer, van Beek et al. 2013). For piping initiation, the current model width of $\mathrm{W}=0.3 \mathrm{~m}$ proves to be sufficient and the induced error for smaller model widths can be extracted from fig. 4. For piping progression however, the numerical models showed that a model width of $0.3 \mathrm{~m}$ is insufficient to fully exploit the 3D flow in all piping development stages, but the influence on the critical head $\Delta \mathrm{H}_{\mathrm{cr}}$ is limited (see fig. 4).

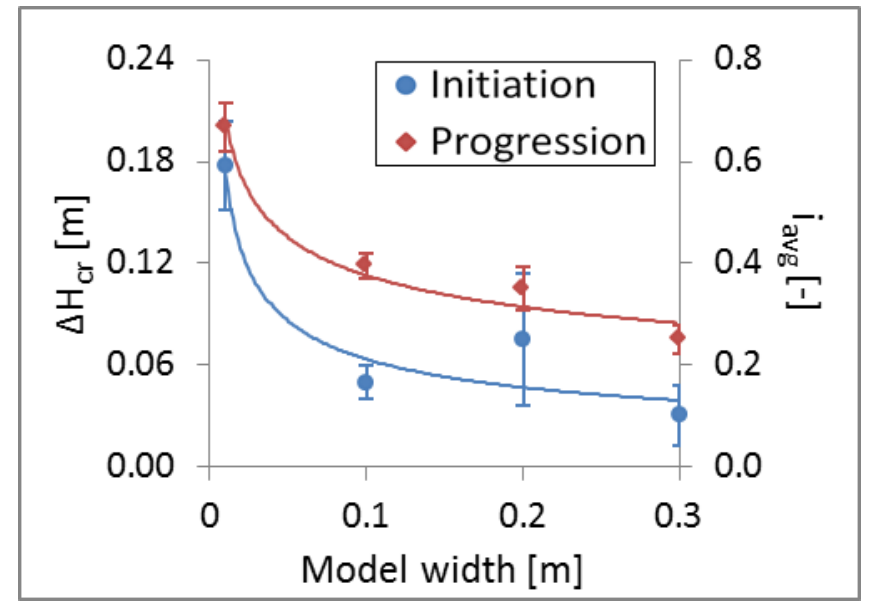

Fig. 4 Critical hydraulic head for piping initiation and progression as a function of the model width; the error bars give the standard deviation from the different tests

For most model widths, the critical head for initiation is lower than the critical head for progression (as opposed to equal), which means that the pipe reaches equilibrium at least once during piping development. Equilibrium is typically encountered in case a hole type exit is 
present (van Beek, Bezuijen et al. 2013). Therefore, piping initiation, i.e. grain ejection and crater formation, does not necessarily lead to failure even if the hydraulic load is maintained constant for a long period. For a model width of $0.01 \mathrm{~m}$ however, which approaches a 2D situation, the critical head for initiation becomes more or less equal to the critical head for progression. Similar behaviour can be observed in case of a plane type exit or a ditch type exit (van Beek, Vandenboer et al. 2014) representing the absence of an impermeable top layer or a ditch downstream from the levee in the field: these are initially $2 \mathrm{D}$ formations, but natural inhomogeneities induce preferential flow paths which lead to erosion affecting the sand layer such that they evolve to 3D situations with periodically spaced outflow openings (Miesel 1978).

The so-called critical pipe length $L_{\text {crit, }}$, i.e. the pipe length projected on the $x$-axis (the actual meandering pipe length is often somewhat longer) which, once surpassed, is not followed by equilibrium anymore if the hydraulic head is kept constant, varies for the different model widths (see table 1) and does not fully correspond to the generally adopted value of L/3 - L/2 (MüllerKirchenbauer, Rankl et al. 1993).

The difference in piping process resulting from the limitation in width, i.e. the relation between initiation and progression, can be illustrated by the flow development during the experiments.

Fig. 5a shows the measured flow rate $Q$ and the corresponding exit velocity $v_{\text {exit }}=Q / A_{\text {exit }}$ (with $\mathrm{A}_{\text {exit }}$ the cross sectional area of the circular exit) as a function of the applied hydraulic head $\Delta \mathrm{H}$ and corresponding average gradient $\mathrm{i}_{\text {avg }}=\Delta \mathrm{H} / \mathrm{L}$. The black crosses indicate the moment of piping initiation $\Delta \mathrm{H}_{\text {init, }}$, i.e. grain ejection from the exit hole; for a model width of $0.2 \mathrm{~m}$ a grey cross is added at the expected critical head for initiation according to fig. 4 as the found average deviates. For smaller hydraulic loads, the measured flow rate $Q$ may be inaccurate and is omitted from the graphs. It is found that piping initiates for all models around $Q=8.8 \cdot 10^{-8} \mathrm{~m}^{3} / \mathrm{s}$ or $v_{\text {exit }}=0.004 \mathrm{~m} / \mathrm{s}$.

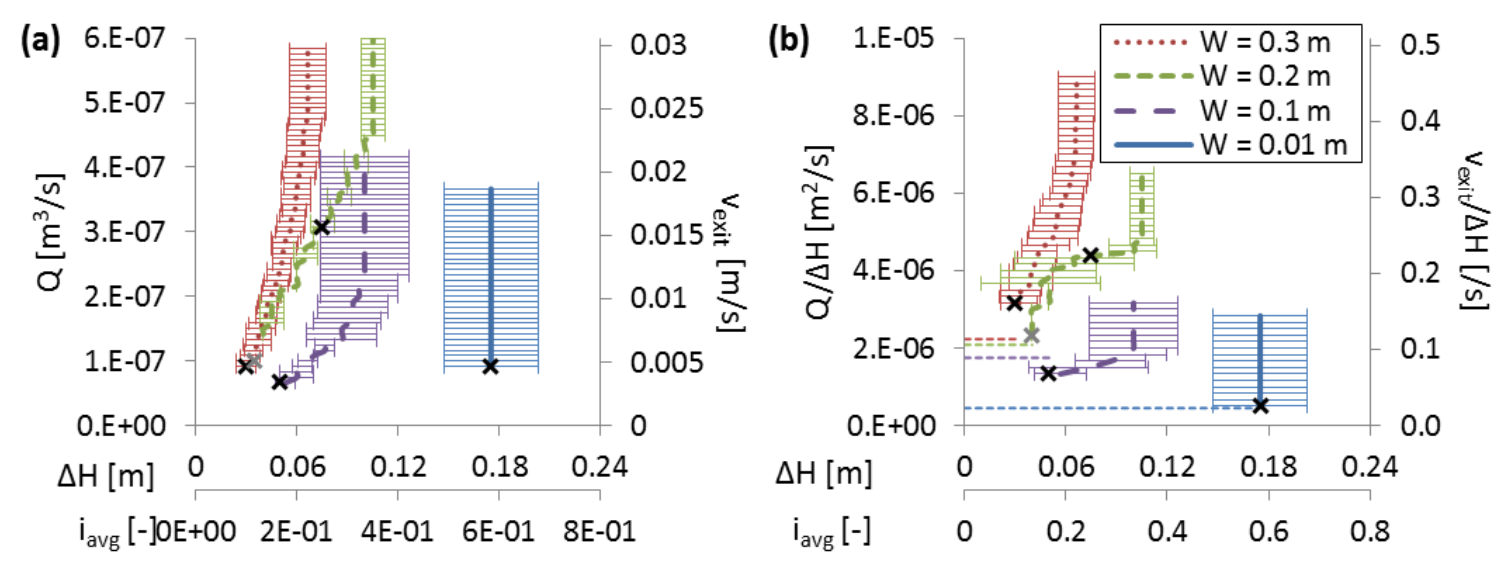

Fig. 5 Flow rate $Q[\mathrm{ml} / \mathrm{min}]$ and exit velocity vexit $[\mathrm{m} / \mathrm{s}]$ (a) and a measure for the overall hydraulic conductivity of the setup $Q / \Delta H[\mathrm{ml} / \mathrm{min} / \mathrm{m}]$ and vexit $/ \Delta H[/ \mathrm{s}](\mathrm{b})$ as a function of hydraulic head $\Delta H[\mathrm{~m}]$ and average gradient iavg [-]; the black crosses corresp

Fig. $5 b$ shows the same results but normalised with the actual hydraulic head, giving a measure for the overall hydraulic conductivity of the sample. For hydraulic loads smaller than $\Delta \mathrm{H}_{\text {init, }}$, the theoretical value for an intact sand bed (using an analytical calculation based on the sum of the 
resistances of parallel flow through the rectangular section and circle symmetric flow towards the exit hole; for $\mathrm{W}=0.3 \mathrm{~m}$ this calculation was checked with a 3D numerical flow calculation and showed good agreement) is added with a dotted line. When erosion occurs, the overall hydraulic conductivity increases. For $\mathrm{W}=0.3 \mathrm{~m}$ this already happens before grains are actually ejected from the exit hole, resulting from fluidisation of the sand below the circular hole. After piping initiation, the hydraulic conductivity increases gradually for the tests with large model widths, which corresponds to the earlier observation of gentle pipe development with several equilibrium stages (strongly progression dominated), opposed to sudden growth without interruption for $\mathrm{W}=0.01 \mathrm{~m}$ (initiation dominated).

\section{Conclusions and recommendations}

A series of small-scale experiments was conducted with a model width varying between $0.01 \mathrm{~m}$ and $0.3 \mathrm{~m}$ to examine the influence of the width of the models on the backward erosion piping process. The flow pattern proves to be highly three dimensional: when increasing the model width, the water supply to the pipe increases because of the bended flow lines in the horizontal plane. Accordingly, the increased water supply facilitates the erosion mechanism both at the tip and in the pipe, and causes the critical head for both piping initiation and piping progression to decrease. It is found that piping initiation is controlled by a critical flow velocity at the exit hole and, for a given hydraulic load, the flow velocity indeed increases with the water supply and thus the model width. However, the contribution of horizontal flow diminishes as flow lines become too long and a minimum width to correctly conduct 3D experiments for this setup was determined. For intermediate model widths (in this study $0.1 \mathrm{~m}$ and $0.2 \mathrm{~m}$ ) the erosion process is similar as for a wide model, but the hydraulic load for both piping initiation and progression is overestimated compared to the experiment with larger width so a correction factor is required. For a model width of $0.01 \mathrm{~m}$ which approaches a $2 \mathrm{D}$ situation, the piping process is different. In this case the pipe covers the entire model width, so inflow parallel to the water-retaining structure and meandering are inhibited. Furthermore, the typical equilibrium stages between piping initiation and progression for experiments with a hole type exit disappear, and the difference in critical head between piping initiation and progression fades away. The flow measurements illustrate the gradual transition from an initiation dominated experiment to progression dominated experiments with increase of model width.

Regarding future research on backward erosion piping, we recommend to take into account the third dimension in both numerical and physical models (sufficiently large width), to correctly simulate the flow towards a circular exit, the flow towards a developed pipe, the erosion at the pipe tip and the pipe development.

\section{Acknowledgements}

The authors would like to acknowledge Ghent University, which funded this project; Sibelco Benelux for providing the sand and Lies Dolphen who performed part of the tests during her master thesis. 


\section{References}

Allan, R., W. Peirson, et al. (2015). Laboratory experiments and numerical modelling of backward erosion piping XVI Dam monitoring international conference 2015, Wierchomla, Poland, Wydawnictw IMGW-PIB, Warschau, Poland.

Bersan, S., A. R. Koelewijn, et al. (2017). "Effectiveness of distributed temperature measurements for early detection of piping in river embankments." Hydrology and Earth System Sciences.

De Wit, J. M., J. B. Sellmeijer, et al. (1981). Laboratory testing on piping. Tenth International Conference on Soil Mechanics and Foundation Engineering. Stockholm, Sweden, AA Balkema: 517-520.

Hanses, U., H. Müller-Kirchenbauer, et al. (1985). Zur Mechanik der rückschreitenden Erosion unter Deichen und Dämmen. Bautechnik. Berlin, Germany, Wilhelm Ernst \& Sohn. 62: 6.

Koito, N., K. Horikoshi, et al. (2016). Physical modelling of backward erosion piping in foundation beneath levee. Scour and Erosion. W. M. Harris. London, Taylor \& Francis Group.

Marot, D., P. Regazzoni, et al. (2011). "Energy-Based Method for providing Soil Surface Erodibility Rankings." Journal of Geotechnical and Geoenvironmental Engineering 137(12): 1290-1293.

Miesel, D. (1978). Rückschreitende Erosion unter bindiger Deckschicht. Deutsche Baugrundtagung. Berlin.

Müller-Kirchenbauer, H. (1978). Zum zeitlichen verlauf der rückschreitenden erosion in geschichtetem untergrund unter dämmen und stauanlagen. Talsperren Symposium, München.

Müller-Kirchenbauer, H., M. Rankl, et al. (1993). Mechanism for regressive erosion beneath dams and barrages. Filters in geotechnical and hydraulical engineering. H. S. Brauns. Rotterdam, Balkema: 369-376.

Sellmeijer, J. B. (1981). Piping due to flow towards ditches and holes. Flow and Transport in Porous Media: proceedings of Euromech 143, Delft, the Netherlands, CRC Press, Boca Raton, FL, USA.

Townsend, F. C., D. Bloomquist, et al. (1988). Evaluation of filter criteria and thickness for mitigating piping in sands. Gainesville, FL, USA, Department of Civil Engineering, University of Florida.

van Beek, V. M., A. Bezuijen, et al. (2013). Backward Erosion Piping. Erosion in Geomechanics Applied to Dams and Levees. S. Bonelli. London, Wiley. 1: 193-269.

van Beek, V. M., A. Bezuijen, et al. (2014). "Initiation of backward erosion piping in uniform sands." Geotechnique 64(12): 927-941.

van Beek, V. M., H. Knoeff, et al. (2011). "Observations on the process of backward erosion piping in small-, medium- and full-scale experiments." European Journal of Environmental and Civil Engineering 15(8): 1115-1137.

van Beek, V. M., K. Vandenboer, et al. (2014). Investigation of the backward erosion mechanism in small-scale experiments. 8th international conference on Physical Modelling in Geotechnics 2014, Perth, Australia, CRC Press, Boca Raton, FL, USA.

Vandenboer, K., V. M. van Beek, et al. (2013). 3D FEM simulation of groudwater flow during backward erosion piping. 5th international Young Geotechnical Engineers' Conference, Paris, France, los Press, Amsterdam, the Netherlands.

Weijers, J. B. A. and J. B. Sellmeijer (1993). A new model to deal with the piping mechanism. Filters in geotechnical and Hydraulical Engineering. J. Brauns, M. Heibaum and U. Schuler. Rotterdam: 349-354. 